\title{
Cognitive procedures as an instrument of translation process analysis
}

\section{[Использование когнитивных аспектов как инструмента в исследовании процесса перевода]}

\author{
Leila Yu. Mirzoyeva - Aleftina A. Golovshun
}

DOI: $10.18355 /$ XL.2016.09.04.9-24

\begin{abstract}
Аннотация
В данной статье затрагивается проблема смены парадигмы в переводоведении и утверждается необходимость междисциплинарного подхода, основанного на взаимосвязи когниции и процесса перевода, к переводческим решениям. Авторами было проведено исследование, которое базировалось на изучении экстериоризированных реакций испытуемых и отражало результаты когнитивных процедур, имевших место в ходе воссоздания разножанровых текстов в процессе перевода.
\end{abstract}

Ключевые слова: когнитивные процедуры, информант, концепт, эталонный перевод, переводческое решение

Введение

Одним из новых направлений в современном языкознании репрезентировано перспективными исследованиями на стыке когнитивной лингвистики и переводоведения. В. З. Демьянков и Е. С. Кубрякова определяют когнитивную лингвистику как отрасль языкознания, которая «изучает язык как когнитивный механизм, играющий роль в кодировании и трансформировании информации» (Dem'jankov, Kubrjakova, 1997: 53). Эта область науки, ввиду своей новизны, дает широкие возможности для исследований и экспериментов.

Актуальность исследований такого рода основана на том, что когнитивная лингвистика является сравнительно новой отраслью науки, которая не только «работает» в поле филологии, но и тесно связана с психологией, психофизиологией, нейролингвистикой, этнолингвистикой и многими другими. С другой стороны, именно подход, декларируемый когнитивной лингвистикой, позволяет объективизировать рассмотрение тех процессов, которые имеют место в ходе воссоздания как отдельных лексических единиц, так и синтагм, и целостных текстов в переводе. Исходя из вышесказанного, в качестве предмета нашего исследования мы избрали изучение взаимосвязи процесса мышления с процессом перевода.

Материалом нашего исследования являются разножанровые и разностилевые тексты: художественный текст («Последний лист» (The Last Leaf) O'Генри- перевод Н. Л. Дарузес), технический текст (инструкция по эксплуатации струйного принтера торговой марки Epson). Выбор столь различного материала обоснован попыткой проследить различия когнитивных процедур, имеющих место в процессе перевода; также представляется интересным проследить степень трудности перевода и количество вариантов, предоставляемых информантами, в первом и во втором случае.

Изучение переводческих решений на базе принципов когнитивной лингвистики было основной целью нашего исследования; помимо этого, нами предпринималась попытка рассмотреть влияние когниции на процесс перевода, а также взаимосвязь языковых преобразований в рамках разножанровых текстов 9

XLinguae Journal, Volume 9 Issue 4, October 2016, ISSN 1337-8384 
и мыслительных процессов в переводческой деятельности. Методика проведения исследования основывалась на проведении переводческого эксперимента в группе из 25 человек, и сопоставлении вариантов перевода, полученных в ходе эксперимента. Безусловно, определенная доля субъективности наличествует в интерпретации данных; но, как указывает М.К. Тимофеева, лингвисты, в отличие от представителей естественных наук, относят такие методы к числу экспериментальных, что на самом деле не лишено оснований, поскольку разграничение так называемых «объективных» и «субъективных» методов отнюдь не просто: субъективные составляющие принципиально неустранимы, поскольку выбором методов, планированием и проведением исследования, интерпретацией его результатов в любом случае занимается человек (Timofeyeva, 2010: 13).

Методологический подход, избранный нами, базируется на работах А.Г. Минченкова (Minchenkov, 2008), Л. М. Алексеевой, Н. В. Шутемовой (Alekseyeva, Shutemova, 2012), А. Г. Минченкова и П. Б. Елпидифорова (Minchenkov, Yelpidiforov, 2002), М.К. Тимофеевой (Timofeyeva, 2010), В. А. Масловой (Maslova, 2007), И.А. Стернина, З.Д. Поповой (Sternin, Popova, 2001), Г. Г. Гадамера (Gadamer, 1991), В. В. Алимова (Alimov, 2005), G. Lakoff (Lakoff, 2004), L. Talmy (Talmy, 1988, 2000) и др.

\section{1. Когнитивные аспекты переводческой деятельности}

\section{1 Когнитивный анализ как инструмент изучения процесса перевода}

В конце XX века языковеды закономерно пришли к выводу, что для решения некоторых проблем лингвистики необходимо выйти за ее пределы, расширить границы познания, обратившись к смежным наукам психолингвистике и социолингвистике, этнолингвистике, герменевтике, нейрофизиологии и антропологии.

В последнее время интерес лингвистов к когнитивным аспектам переводческой деятельности возрастает; в связи с этим фактором, расширяется и сфера применения экспериментальных методов при изучении самого процесса перевода. Это, в свою очередь, постепенной трансформации самой теории перевода от «чисто лингвистических концепций, в рамках которых процесс перевода рассматривался, в основном, как поэтапная трансформация исходного текста на одном языке в текст на другом языке, происходящая благодаря объективно существующим «эквивалентным» отношениям между единицами двух языков на основе выражаемого ими содержания или выполняемой функции, и стремление ученых объяснить явления, происходящие в процессе перевода, с точки зрения когнитивных и речемыслительных процессов, происходящих в голове переводчика-интерпретатора» (Minchenkov, 2008: 4). Постепенно внимание, которое раньше уделялось языковой системе и ее составляющим, концентрируется на личности переводчика. На смену понятиям адекватности, эквивалентности и другим, традиционным для понятийного аппарата лингвистической теории перевода, приходят такие понятия, как когниция, эвристика, концепт, фрейм, роднящие теорию перевода с когнитологией.

Впервые идея о том, что сама лингвистика должна рассматриваться как часть когнитивной психологии, что она должна пересмотреть предмет своего исследования и заняться, в первую очередь, «знаниями говорящих», их языковой компетенцией, отграничив эти знания идеального говорящего от того, как реально говорят и понимают речь обычные люди, озвучил Н. Хомский. 
И.А. Стернин, З.Д. Попова в числе самых актуальных задач современной когнитивной лингвистики, помимо разграничения когнитивной лингвистики и когнитологии, концептосферы и языковой сферы (семантического пространства языка), концепта и языковых средств его выражения; создания типологии концептов и др., говорят о разработке поэтапной методики лингвокогнитивного анализа, которая в опоре на собственно языковые факты и лингвистические методы давала бы когнитивную и культурологическую информацию, раскрывающую различные стороны воплощенных в языке концептов (Sternin, Popova, 2001). Это в полной мере соответствует и задачам переводческой деятельности.

Переосмысление некоторых понятий теории перевода в тесной связи с развитием когнитивной лингвистики происходит по причинам, связанным, в основном, с проблемой обучения переводу. Восприятие перевода как чисто технического процесса устарело, а обучение переводу традиционными методами, без опоры на когнитивные процессы в ходе воссоздания текста, зачастую вызывает непонимание будущих специалистов в сфере перевода и, как следствие, некорректный перевод. Именно эти факторы свидетельствуют о том, что связь языка и мышления, связь когниции и перевода выходят за рамки чисто лингвистических решений.

\section{2 Понятия смысла, мысли и концепта в изучении процесса перевода}

При воссоздании различных текстов, переводчик всегда имеет дело, в первую очередь, с их смысловой стороной. Но имеют ли важную для перевода смысловую нагрузку языковые единицы сами по себе? Мы можем определить смысл как значение, присущее какому-либо слову. Используя определенные слова в своей речи, человек ожидает, что для его собеседника эти слова будут иметь то же значение, что и для него самого, поэтому значение, в определенной степени «привязано» к слову. Как указывает Л.С. Выготский, смысл всегда оказывается динамическим, текучим и сложным образованием. Он субъективен, являясь единицей внутренней речи, и может существовать без слов (Vygotskij, 2003: 284-285). Согласно исследованиям Дж. Олвуда о когнитивных операциях, на процесс формирования смысла влияют три основных фактора: фактор прототипического значения анализируемой единицы, фактор значения других единиц, образующих лингвистическое окружение данной единицы, а также фактор фоновых знаний. $\mathrm{B}$ результате взаимодействия этих факторов становится возможным установить пределы интерпретации смысла (Allwood, 2003). То есть, на значение языковой единицы, помимо концепта, который становится смыслом посредством актуализации, влияют значения языковых единиц, входящих в непосредственное контекстуальное окружение, а также все языковые единицы, которые составляют данную фразу или текст. Как уже указывалось выше, на значение языковой единицы влияют фоновые знания об окружающем мире, которыми обладает переводчик. Все вместе смыслы создают определенную структуру, которая называется концептуальной структурой. Она представляет собой ситуацию, которая описана в предложении, фразе или тексте. Концепт, который представляет смысл, и концепт, который представляет слово, могут отличаться друг от друга, так как зачастую некоторые слова просто не соотносятся с концептами, и наоборот. Как указывают С.Х. Ляпин и Ю.С. Степанов, концепт - единица когнитивного уровня, следовательно, он вбирает в себя все, что принадлежит природе понятия и значения. Но концепт - это и факт культуры, следовательно, он вбирает в себя и то, что делает его таковым: исходная форма (этимология), аксиологическая оценка, ассоциации, 
абстракции, ментальные изоглоссы. Сказанное указывает на сложность выработки единства мнений относительно числа семантических параметров, по которым может вестись его изучение (Lyapin, 1997, Stepanov, 1997, Karasik, 2002). Рассматриваемый с позиций когнитивных операций (а этот угол зрения является одним из наиболее важных, т.к. он позволяет проследить, что именно происходит в скрытой от глаз исследователя мыслительной «творческой лаборатории» переводчика, «концепт - оперативная единица памяти, ментального лексикона, концептуальной системы и языка мозга, всей картины мира, квант знания. Самые важные концепты выражены в языке» (Dem'jankov, Kubrjakova, 1996: 90-92). Что же касается слова, то слово рассматривается в когнитивной лингвистике и в лингвоконцептологии как номинатор, вербализатор концепта, «приводит в движение» фреймы ментального блока (Vardzelashvili, 2004)

Например, идиомы и фразеологические обороты выражают общий смысл всем составом. Так, с помощью английского фразеологического выражения tie the knot обычно называют женатых людей. Следовательно, предложение He decided to tie the knot переводится как Он решил жениться. Таким образом, смысловой концепт «жениться» представлен словесным концептом «tie the knot», который состоит из трех слов. И наоборот, артикли в английском языке, и такие слова, как there в обороте there is выполняют только грамматическую функцию, создавая правильную структуру предложения, не актуализируя концепт.

С другой стороны, концепты могут актуализироваться не только самими знаками, но и определенными их сочетаниями. В этом случае концепт актуализируется лишь благодаря нашим фоновым знаниям и вообще не связан ни с одним словом, то есть невозможно сказать, какое конкретно слово его актуализировало. Так часто происходит, например, при сочетании английского инфинитива в функции определения с существительным или местоимением. В частности, предложение «Не is a man to rely on» дополнительно к концептам, актуализируемым его словами, активирует концепт возможности (Dem'jankov, Kubrjakova, 1996: 125).

Некоторые языковые единицы представляют интенциональные концепты. Частица even, например, актуализирует концепт, содержащий информацию о том, как говорящий представляет норму или, проще говоря, концепт нормы. В свою очередь, использование коммуникантом нестандартных выражений, дает собеседнику представление об уровне образованности оппонента, а также о его социальном положении; либо идентифицировать его как носителя иного языка. Ср.: «Dolittle gets mad at Professor Higgins, she says "and you can* look for someone else to fetch you them slippers every morning!" and Professor Higgins responds, "those slippers..!" (Б. Шоу «Пигмалион»). Очевидно, что использование «them» вместо «those» свидетельствует о низком уровне образования коммуниканта. Ср. также: «Бэгэрэдство! (благородство) презрительно вставил капитан... Он с тобой любезен, стол тебе сервирует, ядовито проговорил капитан (справедливость требует сказать, что он произнес сельвирует» (А.И. Куприн). В подобных случаях срабатывает отчетливо выраженный у каждого носителя языка стереотип: то, что говорящий выражает свои интенции таким образом, - плохо.

После того, как смысл сформирован, происходит следующая стадия нашего мышления, на которой рождается мысль. Эта стадия движения от слова к мысли оказывается «динамическим, неустойчивым, текучим моментом, мелькающим между более оформленными и стойкими крайними полюсами...: между словом и мыслью», моментом, когда вербальные концепты порождают в 
сознании предметные образы и схемы языка мысли и взаимодействуют с ними (Allwood, 2003: 339).

По утверждению В. Беньямина, ни один перевод не был бы возможным, если бы в своей сущности он не стремился бы к подобию исходному тексту, и высшее предназначение перевода заключается в том, чтобы выявить глубинное, а не поверхностное отношение между языками. Выражаемая в языке мысль всегда зависима, так как она прикреплена к словам и словосочетаниям. Языки друг от друга отличаются способами существования слов, которые называют модусами. Например, французское слово mort, немецкое tod и английское death означают одно и то же, но у них разные модусы значения. Перевод же, в свою очередь, позволяет освободить «чистое значение» от языковых форм исходного языка, превратить обозначающее в обозначаемое и вновь обрести чистый язык, который уже ничего не обозначает и не выражает, он просто есть» (Ben'jamin, 1978: 16).

В своем фундаментальном исследовании по когнитивной семантике Л. Тальми обращает внимание на то, что отношение между семантическими элементами (термин, употребляемый Л.Тальми вместо концепт) и поверхностными элементами структуры предложения (словами) часто носит непрямой характер. Набор семантических элементов может выражаться одним поверхностным элементом, и, наоборот, один семантический элемент - целой комбинацией поверхностных элементов. Главное, что это отношение оказывается разным для разных языков. Среди семантических элементов, участвующих в концептуальном представлении события движения, например, Л.Тальми выделяет четыре центральных - субъект, действие, фон и путь, и два факультативных - способ и причину (Talmy, 2000: 21).

Концепты-смыслы обычно скомбинированы относительно значений слов, вокруг которых они образованы, создавая тем самым единую структуру, которая непосредственно зависит в большой мере от контекста. При переводе такого предложения на какой-нибудь язык из романской группы, переводчик столкнется с тем, что ему трудно (зачастую даже невозможно) будет подобрать слово, которое могло бы точно актуализировать этот концепт. Эти же проблемы возникают и при переводе безэквивалентной лексики или же при передаче каких-либо реалий, присущих одной национальности.

\section{2. Взаимосвязь когниции и перевода в переводоведении начала XXI века}

\section{1 Процесс перевода с точки зрения когниции}

Как мы узнали в предыдущей главе, отношения между словом и смыслом не постоянные и устойчивые, а активно изменяющиеся и динамичные. При движении коммуниканта от слова к мысли в сознании актуализируется прототипическое значение слова, от которого посредством процессов интерпретации сознание формирует смысл, и на последнем этапе смыслы, образованные от слов предложения, перетекают в единое мыслительное представление описываемой в предложении ситуации. При движении от мысли к слову происходит обратный процесс - мысль постепенно «совершается в слове» (Allwood, 2003: 293).

В соответствии с когнитивной концепцией перевода. исходный текст ни во что не трансформируется, и его значение никуда не переносится (Minchenkov, 2008: 137; Alekseeva, Shutemova, 2012). Он, тождественный лишь самому себе, в том виде, в каком он создан своим автором, воспринимается переводчиком и служит источником формирования в его сознании 
определенной концептуальной структуры, точно так же, как если бы переводчик воспринимал его не с целью перевода, а как обычный читатель. Концептуальная структура формируется в сознании переводчика на основе текста, но благодаря существованию в его сознании когнитивной структуры знаний. Эта когнитивная структура знаний, как было отмечено, связана интерфейсами с лингвистической информацией и информацией, получаемой посредством восприятия и действия. Благодаря интерфейсу, обвязывающему концепты со звуками или графическими знаками, информация от исходного текста поступает в сознание и актуализирует там соответствующие концепты. При актуализации концептов задействуется, однако, не информация, поступающая от текста, но и та, что идет по другим интерфейсам. Во-первых, переводчик использует свои фоновые знания, в том числе общие знания о мире. Во-вторых, используются знания, возникающие в результате восприятия переводчиком общего контекста речевого взаимодействия (Dem'jankov, Kubrjakova, 1997: 157).

Текст, созданный в процессе перевода, в свою очередь, не является копией исходного текста, потому что он рождается не путем трансформации исходного текста, а путем замещения концепта исходного текста новым смысловым концептом. И здесь снова используются фоновые знания переводчика, но уже связанные с языковой картиной мира языка перевода. В зависимости от фоновых знаний переводчика, а также различных внешних факторов, перевод одного и того же текста у разных авторов получается разным.

\section{2 Использование когнитивных методов в исследовании процесса перевода художественного текста}

Нами было проведено исследование ${ }^{1}$, которое, как указывалось выше, базировалось на изучении экстериоризованных реакций испытуемых. Экспериментальной группе, включавшей 25 человек, были даны тексты, соотносимые с разными жанрами и стилями. Первый текст (художественного стиля) - это фрагмент рассказа О. Генри «The Last Leaf», второй текст (научнотехнического стиля) - фрагмент инструкции по эксплуатации МФУ торговой марки Epson. Переводом этих текстов, который был учтен за эталонный, является: для художественного текста перевод Н. Дарузеса, для технического перевод креативной команды Epson Россия. Все участники эксперимента относятся к одной возрастной группе, а именно от восемнадцати до двадцати одного года, а также одного и того же социального уровня и рода деятельности. Эксперимент проводился на условиях полной анонимности. Причинами, по которым была отобрана именно эта группа, являются доступность участников эксперимента, сходство социального статуса и возрастных характеристик, а также их непосредственная заинтересованность в результате эксперимента. Каждый информант был ознакомлен с целью эксперимента, а также с контекстом каждого из отрывков текста. Уровень фоновых знаний, а также уровень сформированности переводческих умений информантов примерно одинаков. На перевод каждого текста было дано восемь минут. Перевод исследовался с точки зрения соответствия эталонному переводу, соблюдения стилистики текста; также рассматривался перевод отдельных слов и словосочетаний, которые были взяты из контекста. Был проведен сопоставительный анализ переводов всех участников эксперимента, на основе которого были составлены графики частоты использования тех или иных

\footnotetext{
1 Авторы выражают благодарность студенту университета «Туран» (Алматы, Казахстан) Валентину Попову за вклад в организацию и проведение эксперимента
}

14

XLinguae Journal, Volume 9 Issue 4, October 2016, ISSN 1337-8384 
концептов в речи переводящих с учетом точности перевода в условиях ограничения времени и стрессовой ситуации.

Рассмотрим переводы художественного текста. Из 25 текстов, представленных информантами, максимально близкими к эталонному переводу, было два перевода, то есть 8\%. Наибольший интерес для нас составил перевод таких лексических единиц, как oh, such a thing, ivy leaves, vine, don't be silly, let's see exactly what he said, ten to one. В эталонном переводе автор не стал переводить междометие oh, а просто опустил его. Таким же образом поступили $19 \%$ информантов. Наибольшее количество опрошенных, а именно $38 \%$, перевели это междометие как «о». Процентное соотношение остальных ответов указано в Графике 1. Данный график показывает, что перевод одного только междометия может дать до семи различных вариантов, в зависимости от уровня фоновых знаний, а также фантазии переводчика и скорости его мышления. Мы видим в графике наличие стандартных переводов, близких к эталонному, а наличие таких необычных вариантов, как «ого» и «юх», дает нам возможность заметить, что у некоторых информантов когнитивные процессы протекают несколько иначе, чем и продиктованы семантико-стилистические различия. Также можно заметить, что 6\% информантов предпочли не переводить междометие, а просто транслитерировать его.

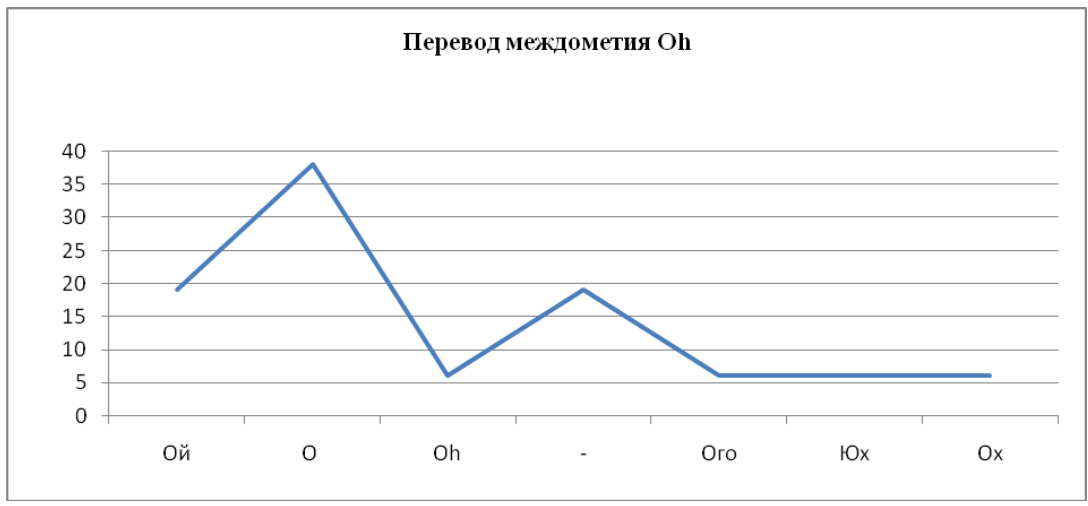

График 1

Словосочетанию such a thing соответствуют 7 вариантов перевода, предложенных нашими информантами. Наиболее близким к эталонному переводу в этот раз оказались 25\% информантов, которые перевели данное сочетание как «об этом» (контекст предложения: In ever heard of such a thing). Такой же процент опрошенных указали в качестве перевода вариант «Такие вещи». Процентное соотношение других ответов указано в Графике 2 


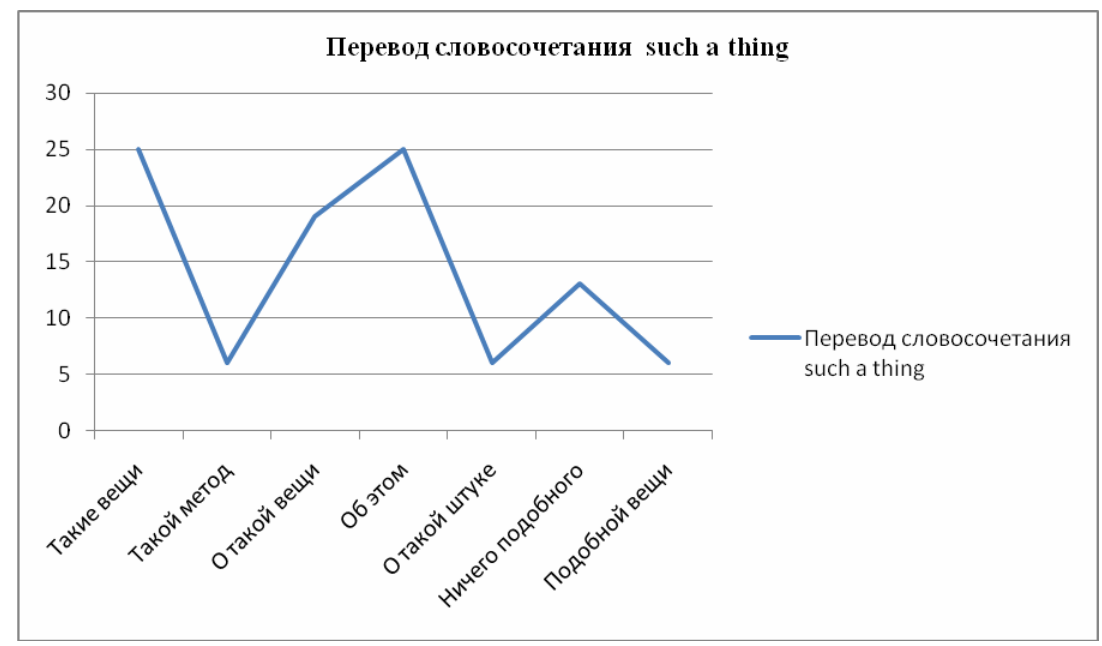

График 2

Как видно из графика, третьим по популярности был ответ «о такой вещи», более дословный перевод выражения. Интересно, что информанты, которые в первом случае составили меньшинство с вариантами переводов «юх» и «ого», в этом случае также составили наименьшее процентное соотношение, а именно предложили варианты «такой метод» и «подобные вещи» соответственно.

Перевод сочетания «ivy leaves» дал нам всего три возможных варианта перевода, причем абсолютное большинство информантов, а именно 63\%, дали перевод, наиболее точный к эталонному. Наименьшее процентное содержание составил вариант «кусочки плюща», которым при переводе воспользовались всего шесть процентов информантов, что примечательно, это те же самые информанты, которые в первых двух вариантах самые нестандартные варианты перевода. Процентное соотношение других вариантов указано на Графике 3.



График 3 
Особый интерес представляют варианты перевода слова «vine». В данном случае информантами предложено пять различных вариантов перевода, причем ни один из них не соответствует эталонному. В соответствии со словарной дефиницией, плющ является ползущим кустарником, придаточные корни которого цепляются за выступы, для дальнейшего произрастания в этом направлении, точно также, как виноград. Поэтому обобщенное «Vine» часть информантов перевели именно как виноград. В Графике 4 показано процентное соотношение переводов этого слова.

Наибольшее процентное соотношение переводов слова, а именно $37 \%$, составляет перевод «лоза», который, если не касаться контекста, является наиболее точным дословным переводом. На втором месте по популярности вариант «вино», хотя в английском языке это слово имеет иной графический облик, что говорит о том, что информанты очень сильно полагаются на ассоциативное мышление и ассоциативные связи при переводе.

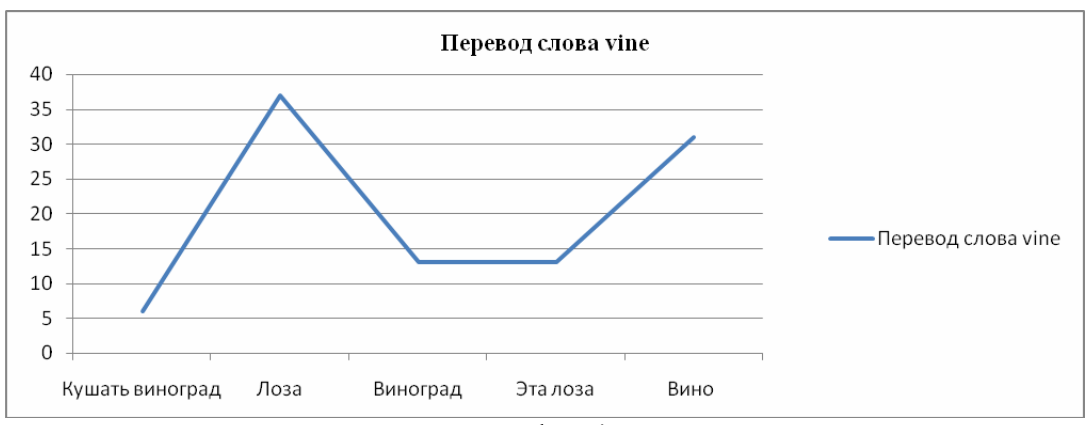

График 4

Наименьшее процентное соотношение составляет вариант «кушать виноград». В этом варианте прослеживается интересная логическая последовательность. Информант, скорее всего, воспринял перевод слова, провел аналогию и сделал вывод, что на лозе должно расти нечто, что может помочь больному человеку (см. контекст) и решил, что именно виноград будет идеальным вариантом.

Перевод следующего фрагмента текста, а именно выражения «don't be silly», несколько озадачил информантов. Если посмотреть на синтаксическую структуру английского выражения и сопоставить ее с предложенными вариантами, мы увидим, что предпочтения информантов лежат в сфере более динамичной и экспрессивной, но в то же время более стилистически нагруженной (негативно оцениваемой с позиций стиля). Возможно, логичнее всего было бы сохранить синтаксическую структуру предложения, но на деле наибольшее количество информантов, а именно $34 \%$, решили исключить концепт, синтаксически представляющий объект (атрибутив), из перевода, значительная часть также предпочла вариант, содержащий атрибутив. В Графике 5 показано процентное соотношение переводов этого выражения. 


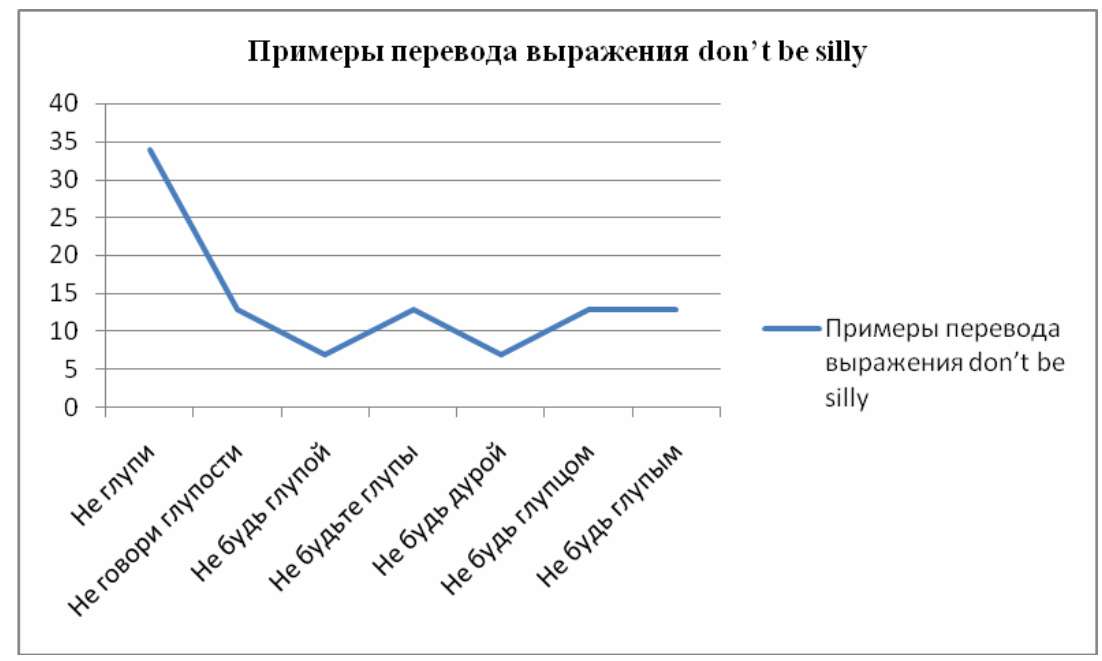

График 5

Наименьшее процентное соотношение составляют варианты «не будь дурой» и «не будь глупой», являющиеся наиболее приближенными к эталонному переводу, который практически без нарушений передает синтаксическую форму исходного предложения.

Наибольшее количество вариантов получилось при переводе выражения let's see exactly what he said. Ни один из информантов не дал перевод, наиболее приближенный к эталонному. Два варианта перевода «посмотрим точно, что он сказал» и «посмотрим, что именно он сказал», которые являются наиболее близкими к оригиналу переводами, составляют всего $17 \%$ и $8 \%$ соответственно, что дает нам возможность сделать вывод о том, что при переводе информанты не руководствовались максимальной приближенностью именно к исходному тексту, а старались передать именно концепт смысла. В Графике 6 показано процентное соотношение других вариантов перевода данного выражения.

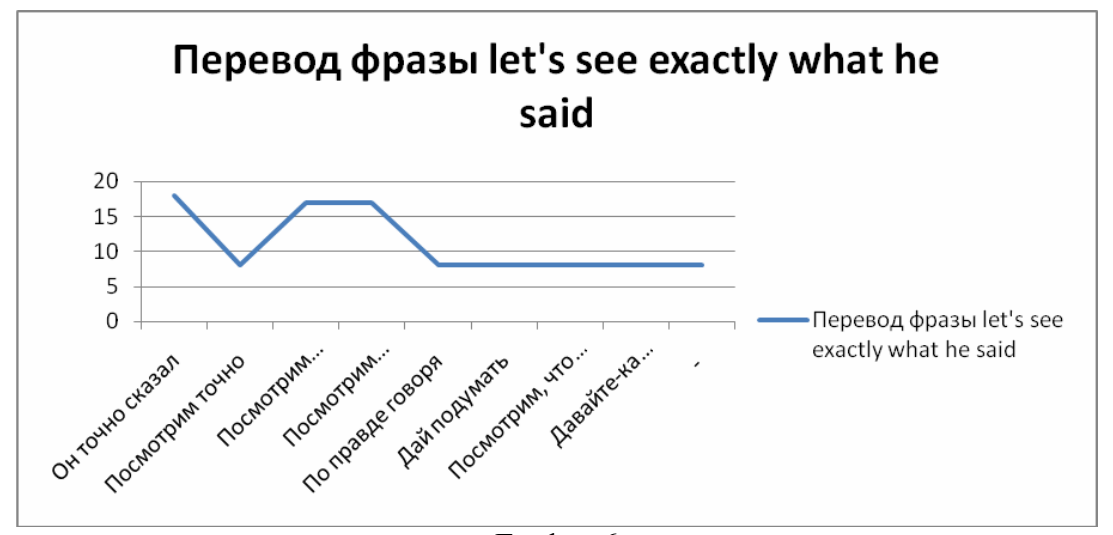

График 6 
Как видно из Графика 6, часть информантов, а именно $8 \%$, просто пропустили это выражение, не посчитав нужным перевести его, или не усмотрев в нем особой смысловой нагрузки.

Перевод выражения «ten to one» мы считаем одним из самых интересных, потому что в данном случае налицо разнообразие вариантов, избранных информантами. Так, часть информантов записала числительные цифрами, часть прописью, а часть использовала как цифры, так и слова. Наиболее популярным ответом стал вариант «10 к 1», который является дословным переводом, который в то же время полностью разрушает концепт исходного текста (в случае цифрового представления, что в большинстве случаев неприемлемо, потому что это ломает всю структуру предложения). Аналогичный вариант, но в словесном выражении, занимает второе место по популярности среди информантов, несмотря на то, что он является более корректным. Примечательно, что одним из самых популярных вариантов среди информантов стал также вариант «один из десяти», который можно назвать вольной интерпретацией слов автора переводчиком. Подробно процентное соотношение вариантов показано в Графике 7.

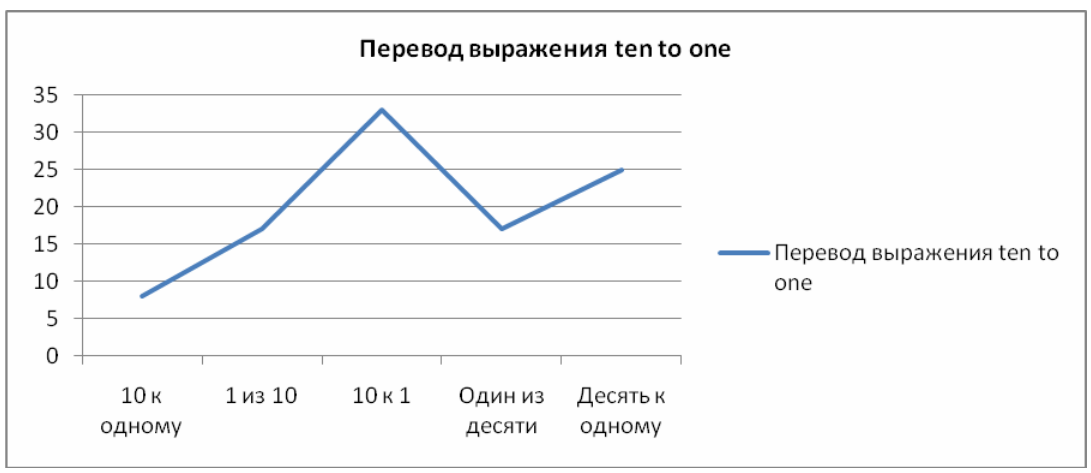

График 7

Примечательно, что вариант, в котором числительные выражены как цифрами, так и словами, являет наименьшее процентное соотношение. В то же время вариантов с использованием цифр столько же, сколько и вариантов, основанных на использовании словесной формы числительных, что может свидетельствовать о том, что в среднем информанты используют и тот и другой метод передачи числительных, в зависимости от каких-либо факторов. В нашем случае, скорее всего, это был фактор ограниченного времени.

Подводя итог рассмотрению перевода художественного текста, следует отметить, что о сохранности концептуальной информации текста, соблюдении его стилистики и адекватности перевода можно говорить в 85\% случаев. Остальные $15 \%$ информантов предоставили лишь частичный перевод, или же нарушили стилистические нормы художественного текста; в это же число входят переводы, не соответствующие требованию адекватности. Стоит особо отметить нескольких информантов, которые при переводе руководствовались не требованием максимальной близости перевода к оригиналу, а продемонстрировали нестандартность мыслительных операций. Нестандартность решений потенциально важна для переводчика именно художественного текста; с другой стороны, в рамках нашего исследования она привела к тому, что процентное соотношение их вариантов перевода всегда 
составляло меньшинство, при этом отличаясь оригинальностью и новизной подачи.

\section{2 Использование когнитивных методов в изучении особенностей перевода технического текста}

Перевод технического текста характеризовался большей степенью сложности, чем художественный, ввиду наличия специфической терминологии. При проверке и анализе переводов, нас заинтересовал перевод трех выражений, а именно «replacing ink cartridges», «printing problem solutions» и «information on Fax specifications». Наиболее близкими к эталонному переводу в этот раз оказались 20\% информантов. Рассмотрим их переводы более детально.

Перевод первого выражения - replacing ink cartridges - дал нам восемь различных вариантов перевода, причем два из них были максимально близки к эталонному переводу, при этом составив всего $6 \%$ и $11 \%$ от общего процентного соотношения. Наибольшее процентное соотношение составляет вариант «замена картриджа», которое стало шаблонным и запечатлелось в качестве клише ввиду частоты употребления. Возможно, поэтому большая часть информантов указала этот вариант, несмотря на то, что в нем имеет место неполное соответствие концептов. В Графике 8 показано процентное соотношение других вариантов перевода.

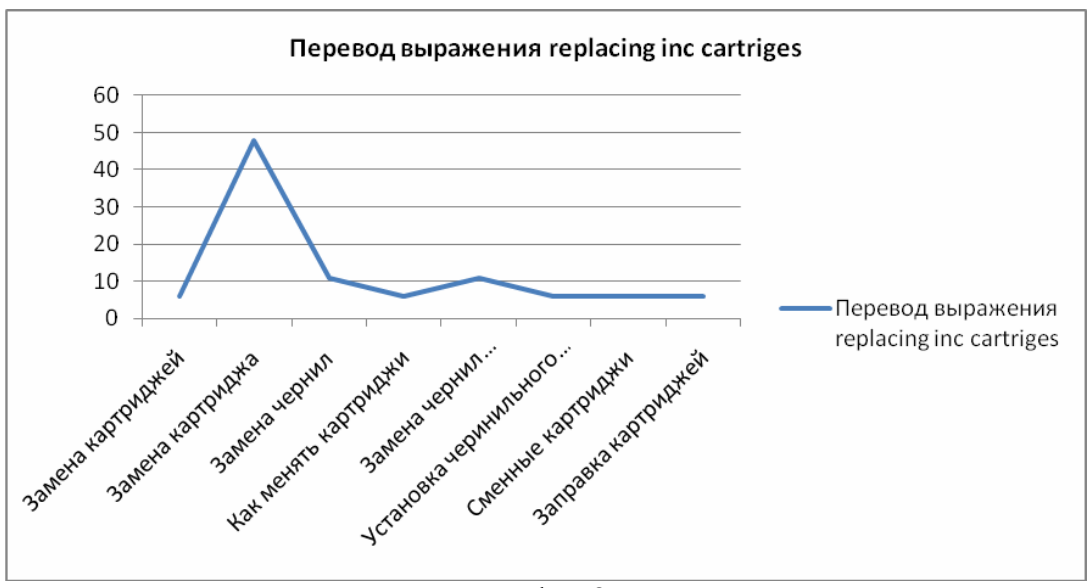

График 8

Следует отметить, что разница между самым популярным ответом («замена картриджа») и самым непопулярным («замена картриджей») почти не существенна, отличие лишь в репрезентации категории числа, но при этом вариант «замена картриджей» был бы более правильным с точки зрения концепта, представленного в оригинальном тексте.

Перевод выражения «printing problem solutions» характеризуется наибольшей вариативностью. Но из двенадцати предложенных нам переводов только один максимально соответствует эталонному переводу, и, что примечательно, это самый непопулярный ответ из всех. Самый популярный ответ - «решение проблем печати» - является наиболее точным переводом исходного выражения, сохраняющим структуру предложения, и, следовательно, схему мыслительной операции, в полной мере. В Графике 9 показано соотношение вариантов перевода. 


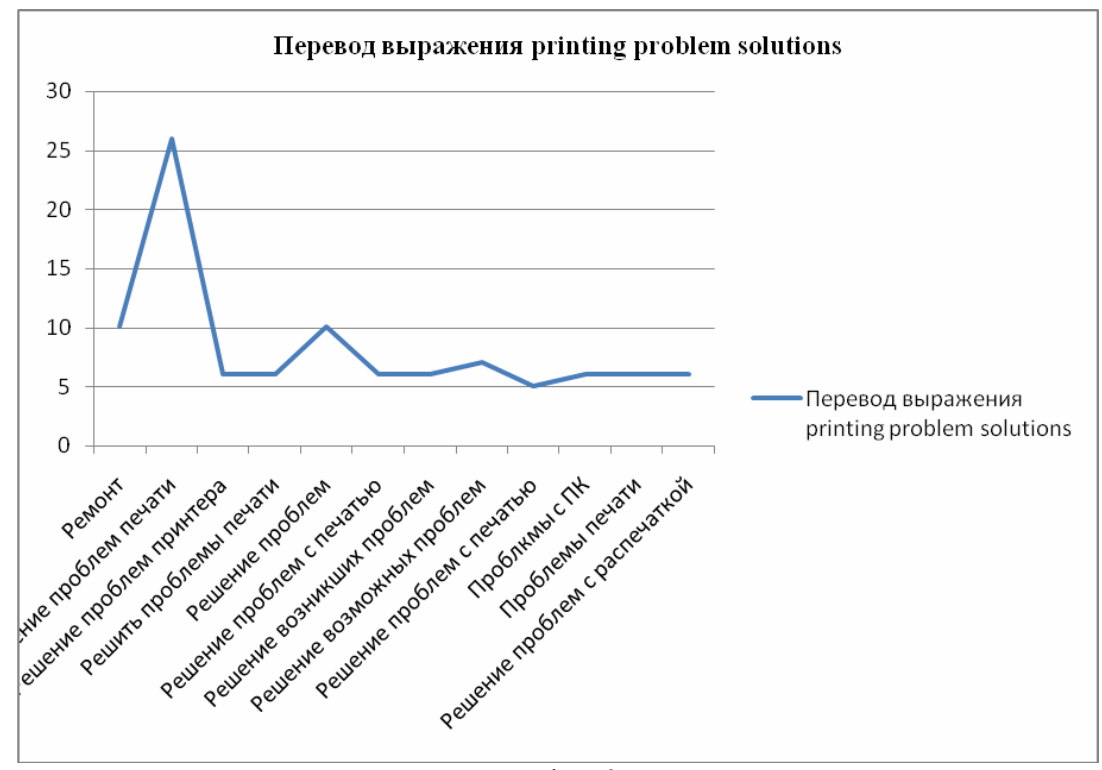

График 9

Примечательно, что вариант «решение возможных проблем» составляет всего лишь 7\%, в то время как он является наиболее корректным и подходящим из всех по контексту. Какой производитель укажет в инструкции, что у пользователя буду проблемы с его продуктом? А вот то, что проблемы возможны, не исключает никто.

Перевод выражения «information on Fax specifications» поставил в тупик большую часть экспериментальной группы. Подавляющее большинство информантов просто пропустило этот фрагмент, аргументируя тем, что наличие услуги факса в данной модели возможно, но не входит в число обязательных характеристик; поэтому, раз ее нет в данной модели, то и переводить это не обязательно. Таким образом, самым популярным ответом среди информантов стал просто пробел. Интересно, что ни один из информантов не был близок к варианту эталонного перевода «отправка факсимильных сообщений». Наименьший процент среди информантов составил вариант «использование функции faх». Примечательно, что эти же информанты не перевели междометие «Oh» в случае с художественным текстом. Это может говорить об определенной стереотипности когнитивных процессов: ведь, если данные информанты сталкиваются с переводом слова или фразы, точного эквивалента которой нет в языке перевода, они предпочитают просто воспроизвести то, что есть в исходном тексте. Кроме того, этот факт свидетельствует и о невысокой скорости нахождения корреспондирующего концепта данным кругом информантов. В Графике 10 показано процентное соотношение других вариантов перевода. 


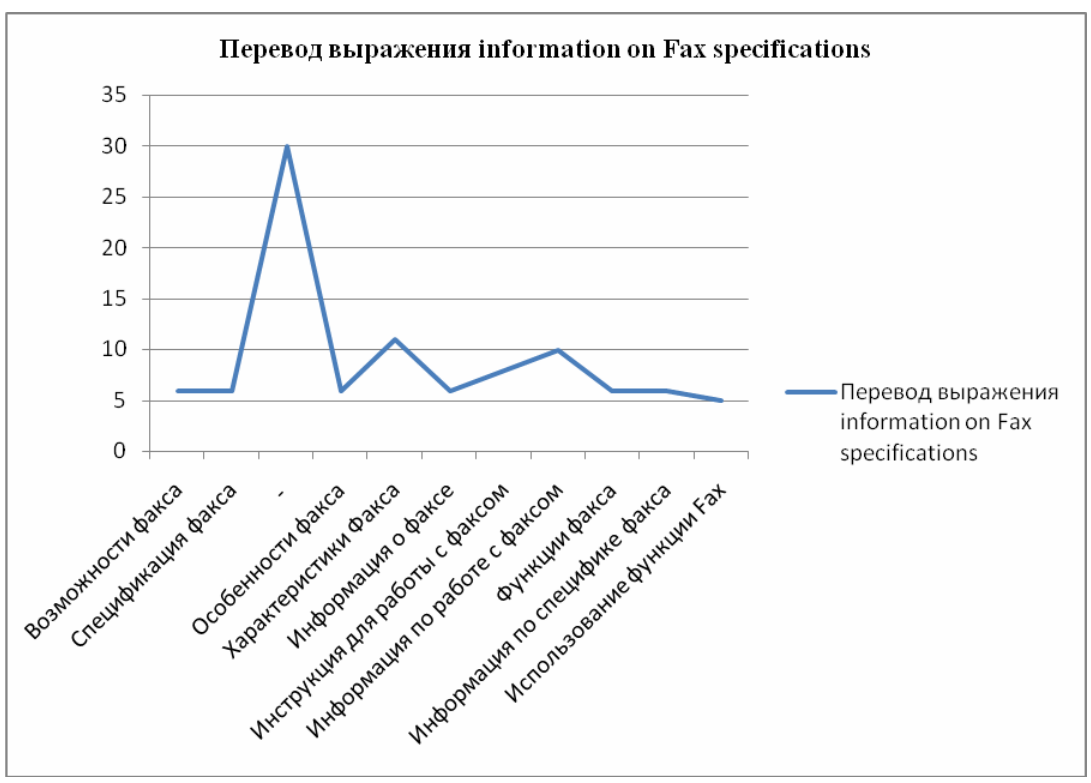

График 10

Подводя итог, можно заключить, что перевод технического текста для информантов представил гораздо более сложную задачу, так как при его переводе полностью с поставленными задачами справились лишь $65 \%$ информантов. $35 \%$ имели трудности с сохранением стиля и адекватностью перевода, причем треть из этой группы информантов не справились с переводом в отведенное на это время. Основываясь на вышесказанном, можно заключить, что для перевода технических текстов требуется больше усилий, что зиждется на задействовании большего количества когнитивных процессов.

\section{Заключение}

Основываясь на проведенных исследованиях и поставленном эксперименте, можно сделать следующие выводы. Во-первых, процесс перевода в настоящее время не может быть полностью автоматизирован, так как язык постоянно совершенствуется и только человек, который использует язык ежедневно и непосредственно сам участвует в его развитии, может создать перевод, который будет считаться адекватным. Помимо этого, сложность когнитивных процедур и реакций информантов свидетельствует о том, что именно гибкость человеческого мышления позволяет добиться наибольшего соответствия авторским интенциям при сохранении семантической и структурной составляющих в случае с художественным текстом.

Во-вторых, использование когниции как инструмента в процессе перевода позволяет переводчику более точно передавать смысл исходного текста, а также улавливать главную мысль и суть. Разложение текста на концепты помогает актуализировать процесс перевода и посмотреть на него с совершенно другой точки зрения, помочь более точно донести мысль до носителя языка перевода, как при устном, так и при письменном переводе. Задействование когнитивных механизмов разума также помогает развивать мышление и совершенствовать 
свои способности не только относительно перевода текстов, но и речевые компетенции в целом.

Результаты исследования, полученные в ходе эксперимента, а также сама экспериментальная процедура, могут быть использованы в альтернативной методике обучения переводу.

В будущем, для более чистой картины исследования планируется провести серию экспериментов, подобных описанному выше, но уже с учетом таких факторов, как социальный статус и фоновые знания информанта, способности к использованию когнитивных механизмов при переводе в стрессовой ситуации и в состоянии спокойствия, индивидуальный и групповой перевод текстов, а также влияние эвристики на перевод и ее взаимосвязь с когницией.

\section{Bibliograpic references}

ALEKSEEVA, L. - SHUTEMOVA, N. 2012 Probuzhdenie perevodovedenija. Perm', Permskij gosudarstvennyj nacional'nyj issledovatel'skij universitet.

ALLWOOD, G. 2003. Pragmatika i kognicija. - Tel' Aviv, Tel'-Avivskij Universitet. BEN'JAMIN, V. 1978. Zadacha perevodchika. - Frankfurt, Surkamp Insel.

KARASIK, V. I. 2002.Jazykovoj krug: lichnost', koncepty, diskurs. Volgograd.

KUBRJAKOVA, E. S. - DEM'JANKOV, V. Z. - PANKRAC ,JU. G. - LUZINA, L. G. 1997. Kratkij slovar' kognitivnyh terminov / Pod obshhej red. E. S. Kubrjakovoj. - M.: Filol. f-t MGU im. M.V. Lomonosova. - 245 s.

LAKOFF, G. 2004. Women, Fire, and Dangerous Things. What Categories Reveal about the Mind. The University of Chicago Press, 1987, pp. 5-15, 39-48, 56-57.// M.: Jazyki slavjanskoj kul'tury, 2004.

LYAPIN, S. H. 1997. Konceptologija: k stanovleniju podhoda // Koncepty. Vyp. I. Arhangel'sk, s.11-35.;

MASLOVA, V. 2008. Kognitivnaja lingvistika. - M., TetraSistems.

MINCHENKOV, A. - ELPIDIFOROV, P. 2002. Metody strukturnoj psihosomatiki. M., Juventa.

MINCHENKOV, A. G. 2007. Kognicija i jevristika v processe perevodcheskoj dejatel'nosti. - M., Antologija.

STEPANOV, JU. S. 1997. Konstanty. Slovar' russkoj kul'tury. Opyt issledovanija. M.

STERNIN, I.A. - POPOVA, Z.D. 2001. Ocherki po kognitivnoj lingvistike, Voronezh.

TALMY, L. 2000. Force Dynamics in language and cognition. - New York, The MIT Press.

TALMY, L. 2000. Toward a cognitive semantics. Vol. 1 // Cambridge.: MIT press, 2000. Cambridge (Mass), L.: A Bradford Book, The MIT Press.

VARDZELASHVILI, ZH. 2004. Koncept kak lingvisticheskaja kategorija «konstruktivnaja sushhnost". - Tbilisskij gosudarstvennyj universitet. Filologicheskij fakul'tet. Sbornik nauchnyh trudov. Tb., s.39-45

VYGOTSKIJ, L.S. 2003 Myshlenie i rech'. // Psiholingvistika v ocherkah i izvlechenijah. Hrestomatija/ Pod obshh. red. V.K. Radzihovskoj. - M. - S. 284-285.

VYGOTSKIJ, L.S.1983. Kul'turno-istoricheskaja psihologija, - M., Pedagogika. 
Words: 4650

Characters: 36065 (18,29 standard pages)

Assoc. Prof. Leila Yu. Mirzoyeva, Doctor of Philology

Department of History and Social Sciences

Suleyman Demirel University

1/1, Abylai-khan str. 050000, Almaty, Kaskelen

Kazakhstan

leyla.mirzoyeva@sdu.edu.kz

Assist.Prof. Aleftina A. Golovshun, Candidate of Pedagogy

Department of Foreign Language Methodology,

Kazakh University of International Relations and World Languages named after Abylai-khan

200, Muratbayev str. 050000, Almaty

Kazakhstan

al_tina@inbox.ru 